\title{
The treatment of chondral and osteochondral defects of the knee with autologous matrix-induced chondrogenesis (AMIC): method description and recent developments
}

\author{
Jan Philipp Benthien • Peter Behrens
}

Received: 18 July 2010/Accepted: 6 December 2010/Published online: 14 January 2011

(C) Springer-Verlag 2011

\begin{abstract}
Purpose Articular resurfacing by treatment of chondral defects may include chondral abrasion, autologous chondrocyte Implantation (ACI), matrix-induced chondrocyte transplantation (MACT) or osteochondral autologous transplantation (OATS). This technical note describes the method of autologous matrix-induced chondrogenesis (AMIC), a one-step procedure combining subchondral microfracture with the fixation of a collagen I/III membrane with fibrin glue or sutures.

Methods This is a technical note on the AMIC procedure and its further development.

Results and conclusion This method is applied primarily in chondral or osteochondral lesions of the knee. Indications and contraindications are provided; the technique is described. The further development of AMIC is described with an increased focus on the subchondral zone and the complex of cartilage and bone, the osteochondral unit, which receives increased attention in cartilage research. Level of evidence IV.
\end{abstract}

Keywords Chondral defects · Osteochondral defects · AMIC · Microfracturing

\footnotetext{
J. P. Benthien ( $₫)$

Department of Orthopaedic Surgery, University of Basel,

Spitalstr. 21, 4031 Basel, Switzerland

e-mail: jbenthien@uhbs.ch

P. Behrens

Department of Orthopaedic Surgery, University of Luebeck,

Luebeck, Germany
}

\section{Introduction}

Chondral or osteochondral defects are of particular interest for the orthopaedic surgeon as these normally do not heal spontaneously. During the past 20 years regenerative techniques applying collagen membranes on treated cartilage defects were developed. It was demonstrated that these collagen II membranes facilitate differentiation of MSCs into chondrocytes whilst providing a scaffold for the chondrocytes to form cartilage [14, 21]. Fixation of the scaffold with commercially available fibrin glue seems to be advantageous as fibrin glue seems to act as an additional scaffold for chondrocytes and that its contents in TGF $\beta$ are considerable, possibly helping in differentiation of mesenchymal stem cells [14].

The cartilage resurfacing procedures most frequently applied are as follows: abrasion arthroplasty and debridement [7, 12], the autologous chondrocyte implantation (ACI) as introduced by Brittberg [8, 9, 16, 18], the method of microfracturing as developed by Steadmann $[22,23]$ and the osteochondral autologous transplantation system (OATS) [6].The ACI involves a two-step procedure transplanting chondrocytes previously taken from a donor site into a cartilage defect [8, 9]. In microfracturing, the calcified subchondral bone/cartilage border is perforated, consecutively fibrous cartilage is developed from mesenchymal stem cells [22, 23]. OATS means taking autologous osteochondral grafts from a non-weight bearing joint site and transplanting them to the defect $[2,6,11]$.

The matrix associated chondrocyte transplantation (MACT) is a further development in cartilage resurfacing which allows previously harvested chondrocytes to differentiate into chondrocytes with the aid of a collagen scaffold $[1,3]$. 
The autologous matrix-induced chondrogenesis (AMIC) as first introduced by Behrens et al. [4, 13] further develops the matrix/scaffold technique in combination with microfracturing. It is a less-expensive one-step procedure which combines microfracturing of the cartilage/bone-lamina after debridement of the cartilage lesion with fixation of a commercially available porcine collagen I/III matrix. This matrix covers the blood clot and its mesenchymal stem cells (MSCs) whilst permitting the MSCs to develop into chondrocytes $[4,13,14,19]$.

The objective of this technical note is to demonstrate the AMIC technique in its original form and its further development and to compare its results with the literature.

\section{Technical note}

Indications for AMIC are symptomatic full thickness (ICRS grade 4) lesions and osteochondral lesions such as in osteochondrosis dissecans. The lesion should not exceed $1.5 \mathrm{~cm}^{2}$, and the location should normally be in the weight bearing region, bearing the highest risk for degenerative joint disease. Contraindications are kissing or multiple lesions, inflammatory diseases such as rheumatoid arthritis, tumour, an uncorrected ligamentous balancing or lesions of the cruciate and collateral ligaments, extension deficit of more than $10^{\circ}$, flexion deficits of more than $100^{\circ}$, malalignment and associated fractures. If an osteochondral defect is present, the author's preferred method is the closure of the osseous defect with an autologous bone transplant from the tibial head which may be harvested during the same procedure. The cancellous bone is impacted into the defect, and the membrane is attached on the defect with either fibrin glue or sutures.

The procedure starts with an arthroscopy of the affected joint to verify the size and location of the defect and also the amount of accompanying disorder. After determining the size and location and after a diagnostic arthroscopy ruling out accompanying lesions or ligamentous problems, an AMIC procedure may be initiated. A minimally invasive arthrotomy is performed and the defect is visualized openly. The defective cartilage tissue and subchondral bone is removed with a curette (Fig. 1a).

If an osteochondral lesion is present, cancellous bone may be harvested from the tibial head using the same incision. An aluminium template may be used to determine the size of the lesion and the appropriate membrane (Fig. 1b).

Membrane and template should be slightly undersized to avoid dislocation after movement. Microfracturing used to be performed in the original method described by Behrens et al. $[4,13]$ with the corresponding microfracturing awls. We have further developed the perforation of the

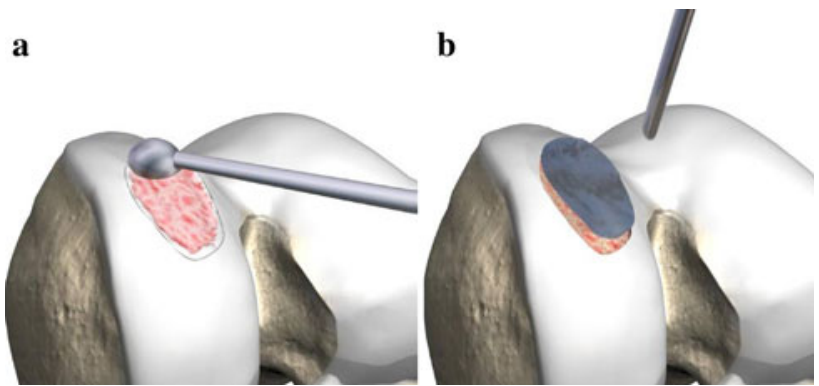

Fig. 1 Curettage of the defect and measuring of an aluminium template

subchondral zone according to the latest literature studies which seem to demonstrate that the subchondral stroma is better reached by drilling [10, 16]. A $1.1 \mathrm{~mm} \mathrm{~K}$-wire is now drilled either by hand or by machine with constant cooling being applied so the subchondral bone is reached (Figs. 2, 3a).

A partially autologous fibrin glue may be manufactured by centrifuging a blood sample from the patient and mixing the yielded thrombin with allogenic fibrinogen from commercially available fibrin glue. Commercially available allogenic fibrin glue or suturing for fixation may also be applied (Fig. 3b).

Suturing, however, may lead to cartilage damage [3]. Knecht et al. [17] have confirmed that glueing with fibrin

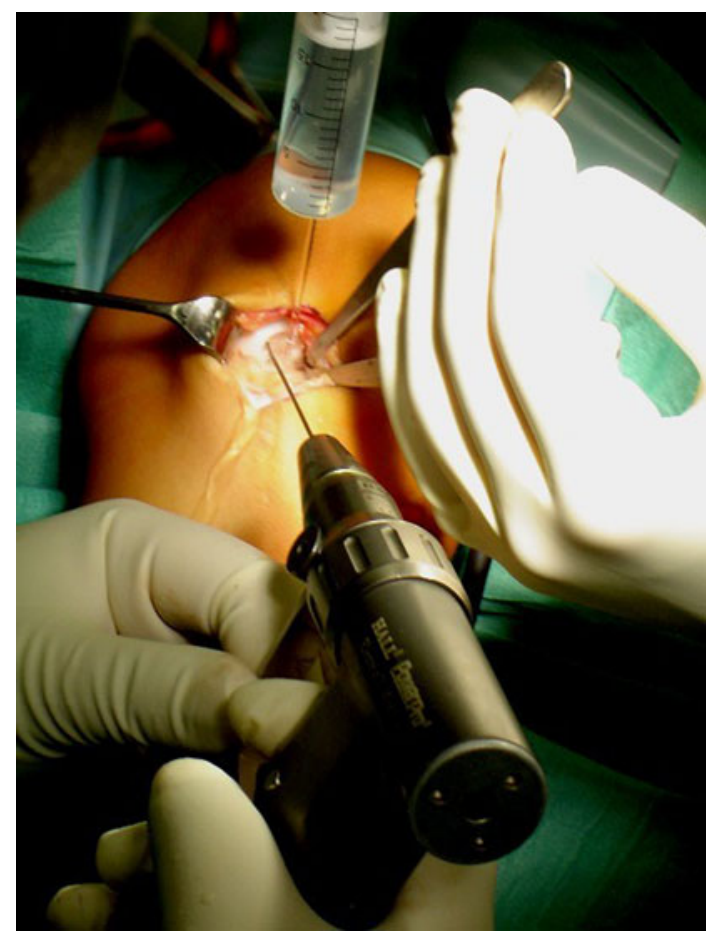

Fig. 2 Microfracturing should be performed with a $1.1 \mathrm{~mm} \mathrm{~K}$-wire which is the author's preferred method of treatment. Cooling with sterile $\mathrm{NaCl}$ solution is advisable. Drilling seems to reach the subchondral bone better than microfracturing alone 

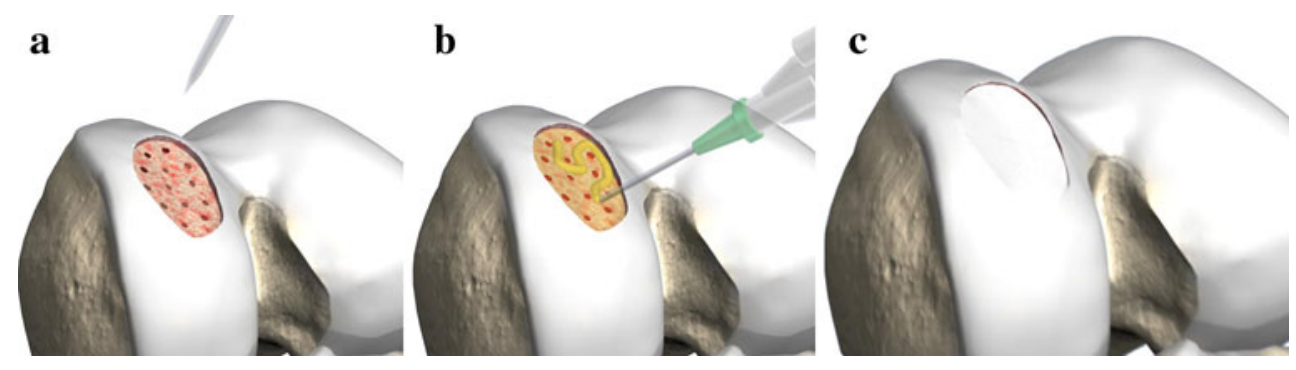

Fig. 3 a-c After microfracturing of the defect, fibrin glue is applied and the collagen II membrane attached. From Gille et al.: Mid-term results of autologous matrix-induced chondrogenesis for treatment of focal cartilage effects in the knee, Knee Surg Sports Traumatol Arthrosc 2010

glue leads to sufficient stability of a collagen membrane. It is important that the collagen membrane is placed slightly below the cartilage level because displacement after moving the joint is almost certain if the membrane stays above the cartilage rim. (Fig. 3c).

The joint should be gently moved intra-operatively. Inspection of the site is advisable and should confirm that the membrane remains in place.

The postoperative management is as follows: maximum weight bearing $15-20 \mathrm{~kg}$ for 6 weeks, common thrombose prophylaxis with a low molecular heparin, and continuous joint movement. Removal of a possible drain $24 \mathrm{~h}$ after surgery is recommended. Care should be exercised that the suction is removed as this could lead to membrane dislocation.

Maximum flexion of the knee should not exceed $30^{\circ}$ for 2 weeks following the operation. Flexion is raised to 60 and $90^{\circ}$ for another 2 weeks, respectively. The patient is seen in the outpatient clinic 6 weeks after the appointment.

\section{Discussion}

The most important feature of the present technical note is the introduction of a combined microfracturing and collagen method for cartilage surgery which is further developed according to the latest findings in cartilage physiology.

Chondral or osteochondral injuries affect a broad spectrum of patients with knee pain. They may be either posttraumatic or with an unknown cause such as osteochondrosis dissecans. Young active adults may be involved. These defects may eventually lead to progressive joint destruction by osteoarthritis, thus gaining significant interest by the orthopaedic surgeon to develop proper treatment. However, as many studies treat this subject, no procedure may be recommended as the treatment of choice at this time [5].

Gille et al. [13] reported good mid-term results of AMIC reporting that $87 \%$ of the treated patients were highly satisfied with the result. This compares well with the results after microfracturing alone [20, 22, 23].
Drilling does not seem to have such a deleterious effect on the subchondral bone matrix as was once expected but instead leads to better access to the bone-marrow stroma in the rabbit model [10]. A study of de Girolamo et al. [15] suggests a difference in mesenchymal stem cells (MSCs) harvested after microfracturing and primarily from the iliac crest. It is suggested that the MSCs from the microfractured areas demonstrate a different and comparatively irregular pattern than those harvested from the iliac crest.

Following these new findings in cartilage surgery research, the authors have, therefore, modified the original AMIC method and switched from conventional microfracturing awls to drilling with $\mathrm{K}$ wires. It seems to become increasingly important to include the osteochondral unit into cartilage surgery rather than focus on the cartilage alone as this is likely a complex system including interaction between bone and cartilage [16].

The AMIC procedure was developed as a one-step procedure that may be cost-effective and qualify for reimbursement by the health insurances. It has the advantage of a one-step procedure that combines microfracturing with chondrocyte differentiation from MSCs on a collagen matrix. The initially formed blood clot as produced by microfracturing is protected by the collagen membrane. However, since this is a new method, it has yet to show its advantages over microfracturing or simple débridement alone. A disadvantage which may be minimized by minimally invasive methods is the open procedure. Prospective randomized studies should be implemented investigating this method, especially in comparison with microfracturing alone.

The AMIC procedure may be a cost-effective option for the surgeon treating cartilage defects. It is easy to apply, and it supplies the cartilage surgeon with a procedure to offer a patient with a symptomatic cartilage defect.

\section{Conclusion}

Combining micro-fracturing with a collagen I/III scaffold may be a cost-effective option for articular resurfacing by 
treating chondral or osteochondral defects. More prospective randomized Level of Evidence 1 and 2 studies should compare the results of the AMIC procedure as compared to micro-fracturing alone and MACI, both related to AMIC but more cost intensive. Drilling the subchondral zone and reaching the bone-marrow stroma may be more effective than microfracturing with an awl alone.

\section{References}

1. Bartlett W, Skinner JA, Gooding CR, Carrington RWJ, Flanagan AM, Briggs TWR, Bentley G (2005) Autologous chondrocyte implantation versus matrix-induced autologous chondrocyte implantation for osteochondral defects of the knee. A prospective randomized study. J Bone Joint Surg Br 87:640-645

2. Behrens P, Bosch U, Bruns J et al (2004) Indications and implementation of recommendation of the working group "Tissue regeneration and Tissue Substitution" for autologous chondrocyte transplantation. Z Orthop Ihre Grenzgeb 142:529-539

3. Behrens P, Bitter T, Kurz B et al (2006) Matrix associated autologous chondrocyte transplantation: a 5 year follow up. Knee 13:194-202

4. Benthien JP, Behrens P (2010) Autologous matrix-induced chondrogenesis (AMIC): a one step procedure for retropatellar articular resurfacing. Acta Orthop Belg 76:260-263

5. Benthien JP, Schwaninger M, Behrens P (2010) We do not have evidence based methods for the treatment of cartilage lesions in the knee. Knee Surg Sports Traumatol Arthrosc. doi: 10.1007/s00167-010-1271-5

6. Bentley G, Biant LC, Carrington RW, Akmal M, Goldberg A, Williams AM, Skinner JA, Pringle J (2003) A prospective, randomised comparison of autologous chondrocyte implantation versus mosaicplasty for osteochondral defects in the knee. J Bone Joint Surg Br 85:223-230

7. Bert JM, Maschka K (1989) The arthroscopic treatment of unicompartimental gonarthrosis: a five year follow up study of abrasion arthroplasty plus arthroscopic débridement and arthroscopic débridement alone. Arthroscopy 5:25-32

8. Brittberg M (2008) Autologous chondrocyte implantation-technique and long-term follow-up. Injury 39:S40-S49

9. Brittberg M, Lindahl A, Nilsson A, Ohlsson C, Isaksson O, Peterson L (1994) Treatment of deep cartilage defects in the knee with autologous chondrocyte transplantation. N Engl J Med 14:889-895

10. Chen H, Sun J, Hoemann C, Lascau-Coman V, Ouyang W, Trankhanh N, Chevrier A, McKee M, Shive M, Buschmann M (2009) Drilling and microfracture lead to different bone structure and necrosis during bone-marrow stimulation for cartilage repair. J Orthop Res 11:1432-1438
11. Dozin B, Malpeli M, Cancedda R, Bruzzi P, Calcagno S, Molfetta L, Priano F, Kon E, Marcacci M (2005) Comparative evaluation of autologous chondrocyte implantation and mosaicplasty: a multicentered randomized clinical trial. Clin J Sport Med 15:220-226

12. Friedmann MJ, Berasi CC, Fox JM et al (1984) Preliminary results with abrasion arthroplasty in the osteoarthritic knee. Clin Orthop Rel Res 18:200-205

13. Gille J, Schuseil E, Wimmer J, Gellissen J, Schulz AP, Behrens P (2010) Mid-term results of Autologous Matrix Induced Chondrogenesis for treatment of focal cartilage defects in the knee. Knee Surg Sports Traumatol Arthrosc 18:1456-1464

14. Gille J, Meisner U, Ehlers EM, Mueller A, Russlies M, Behrens P (2005) Migration pattern, morphology and viability of cells suspended in or sealed with fibrin glue: a histomorphologic study. Tissue Cell 37:339-348

15. de Girolamo L, Bertolini G, Cervellin M et al (2010) Treatment of chondral defects of the knee with one step matrix assisted technique enhanced by autologous concentrated bone marrow: in vitro characterisation of mesenchymal stem cells from iliac crest and subchondral bone. Injury 41:1172-1177

16. Gomoll AH, Madry H, Knutsen G, van Dijk N, Seil R, Brittberg M, Kon E (2010) The subchondral bone in articular cartilage repair: current problems in the surgical management. Knee Surg Sports Traumatol Arthrosc 18:434-447

17. Knecht S, Erggelet C, Endres M, Sittinger M, Kaps C, Stuessi E (2007) Mechanical testing of fixation techniques for scaffoldbased tissue-engineered grafts. J Biomed Mater Res B Appl Biomater 83:50-57

18. Knutsen G, Drogset JO, Engebretsen L, Grøntvedt T, Isaksen V, Ludvigsen TC, Roberts S, Solheim E, Strand T, Johansen O (2007) A randomized trial comparing autologous chondrocyte implantation with microfracture. Findings at five years. J Bone Joint Surg Am 89:2105-2112

19. Kramer J, Boehrnsen F, Lindner U, Behrens P, Schlenke P, Rohwedel J (2006) In vivo matrix guided human mesenchymal stem cells. Cell Mol Life Sci 6:616-626

20. Mithoefer K, Wiliams RJ, Potter WarrenRF, HG SpockCR, Jones EC, Wickiewicz T, Marx RG (2005) The microfracture technique for the treatment of articular cartilage lesions in the knee. A prospective Cohort study. J Bone Joint Surg Am 87:1911-1920

21. Skodacek D, Rotter N et al (2008) Growth factors and scaffold composition influence properties of tissue engineered human septal cartilage implants in a murine model. Int J Immunopathol Pharmacol 21:807-816

22. Steadman JR, Briggs KK, Rodrigo JJ, Kocher MM, Gill TJ, Rodhen WG (2003) Outcomes of microfracture for traumatic chondral defects of the knee-average 11 year follow up. Arthroscopy 15:477-484

23. Steadman JR, Rodkey WG, Rodrigo JJ (2001) Microfracture: surgical technique and rehabilitation to treat chondral defects. Clin Orthop Relat Res 391:S362-S369 